\title{
Microbial communities in a dynamic in vitro model for the human ileum resemble the human ileal microbiota
}

Citation for published version (APA):

Stolaki, M., Minekus, M., Venema, K., Lahti, L., Smid, E. J., Kleerebezem, M., \& Zoetendal, E. G. (2019). Microbial communities in a dynamic in vitro model for the human ileum resemble the human ileal microbiota. Fems Microbiology Ecology, 95(8), 1-13. [fiz096]. https://doi.org/10.1093/femsec/fiz096

Document status and date:

Published: 01/08/2019

DOI:

10.1093/femsec/fiz096

Document Version:

Publisher's PDF, also known as Version of record

Document license:

Taverne

Please check the document version of this publication:

- A submitted manuscript is the version of the article upon submission and before peer-review. There can be important differences between the submitted version and the official published version of record.

People interested in the research are advised to contact the author for the final version of the publication, or visit the DOI to the publisher's website.

- The final author version and the galley proof are versions of the publication after peer review.

- The final published version features the final layout of the paper including the volume, issue and page numbers.

Link to publication

\footnotetext{
General rights rights.

- You may freely distribute the URL identifying the publication in the public portal. please follow below link for the End User Agreement:

www.umlib.nl/taverne-license

Take down policy

If you believe that this document breaches copyright please contact us at:

repository@maastrichtuniversity.nl

providing details and we will investigate your claim.
}

Copyright and moral rights for the publications made accessible in the public portal are retained by the authors and/or other copyright owners and it is a condition of accessing publications that users recognise and abide by the legal requirements associated with these

- Users may download and print one copy of any publication from the public portal for the purpose of private study or research.

- You may not further distribute the material or use it for any profit-making activity or commercial gain

If the publication is distributed under the terms of Article $25 \mathrm{fa}$ of the Dutch Copyright Act, indicated by the "Taverne" license above, 


\title{
Microbial communities in a dynamic in vitro model for the human ileum resemble the human ileal microbiota
}

\author{
Maria Stolaki ${ }^{1,2,3}$, Mans Minekus ${ }^{3}$, Koen Venema ${ }^{1,4}$, Leo Lahti ${ }^{2,5, \dagger}$, Eddy \\ J. Smid ${ }^{1,6}$, Michiel Kleerebezem ${ }^{1,2,7, *}$ and Erwin G. Zoetendal ${ }^{1,2}$
}

${ }^{1}$ Top Institute Food and Nutrition, P.O. Box 557, 6700 AN Wageningen, the Netherlands, ${ }^{2}$ Laboratory of Microbiology, Wageningen University \& Research, Stippeneng 4, 6708 WE Wageningen, the Netherlands, ${ }^{3}$ The Netherlands Organization for Applied Scientific Research (TNO), PO Box 360, 3700 AJ Zeist, The Netherlands, ${ }^{4}$ Maastricht University - Campus Venlo, Centre for Healthy Eating \& Food Innovation, St. Jansweg 20, 5928 RC Venlo, The Netherlands, ${ }^{5}$ Department of Mathematics and Statistics, FI-20014 University of Turku, Finland, ${ }^{6}$ Laboratory of Food Microbiology, Wageningen University \& Research, P.O.Box 17, 6700 AA Wageningen, the Netherlands and ${ }^{7}$ Host-microbe Interactomics Group, Wageningen University \& Research, De Elst 1, 6708 WD, Wageningen, the Netherlands

\footnotetext{
*Corresponding author: Host-microbe Interactomics Group, Wageningen University \& Research, De Elst 1, 6708 WD, Wageningen, the Netherlands. Tel: +31317483822; E-mail: michiel.klerebezem@wur.nl

One sentence summary: In this study an in vitro model system was developed that simulates the human terminal small intestine and its microbiota. Editor: Cindy Nakatsu

${ }^{\dagger}$ Leo Lahti, http://orcid.org/0000-0001-5537-637X
}

\begin{abstract}
The important role for the human small intestinal microbiota in health and disease has been widely acknowledged. However, the difficulties encountered in accessing the small intestine in a non-invasive way in healthy subjects have limited the possibilities to study its microbiota. In this study, a dynamic in vitro model that simulates the human ileum was developed, including its microbiota. Ileostomy effluent and fecal inocula were employed to cultivate microbial communities within the in vitro model. Microbial stability was repetitively achieved after 10 days of model operation with bacterial concentrations reaching on average $10^{7}$ to $10^{8} 16 \mathrm{~S}$ rRNA copy numbers/ml. High diversities similar to those observed in in vivo ileum samples were achieved at steady state using both fecal and ileostomy effluent inocula. Functional stability based on Short Chain Fatty Acid concentrations was reached after 10 days of operation using fecal inocula, but was not reached with ileostomy effluent as inoculum. Principal Components and cluster analysis of the phylogenetic profiles revealed that in vitro samples at steady state clustered closest to two samples obtained from the terminal ileum of healthy individuals, independent of the inoculum used, demonstrating that the in vitro microbiota at steady state resembles that of the human ileum.
\end{abstract}

Keywords: microbiota; in vitro model; ileum; gut health; microbial diversity; short chain fatty acids 


\section{INTRODUCTION}

The human gastrointestinal tract (GIT) harbors a myriad of microbes playing a crucial role in health and disease (Sekirov et al. 2010; Ottman et al. 2012; Feng et al. 2018). Although most studies on the GIT microbiota focus on the colon and in fact on fecal microbiota, it is evident that the microbiota at other locations in the intestine, such as the small intestine, also plays a crucial role for human health (El Aidy, van den Bogert and Kleerebezem 2015). The small intestine harbors microbial communities that differ in composition to those in the colon and are of substantially lower density (Booijink et al. 2010; Zoetendal et al. 2012; Sundin et al. 2017). The small intestine comprises of distinct anatomical regions, which are the duodenum, the jejunum and the ileum. In the duodenum, the continuation of the enzymatic breakdown, which starts in the mouth, and uptake of nutrients takes place facilitated by pancreatic enzyme secretion and bile. In the jejunum, digestion and absorption continues while in the terminal regions of the small intestine, ileum and the terminal ileum, that occupy $3 / 5$ th of the total length of the small intestine (Kararli 1995), digestion of nutrients occurs that escaped digestion so far. The digested products that are absorbed overall in the small intestine represent nearly $90 \%$ of the energy uptake from the diet. Microbial colonization in the proximal small intestine is strongly inhibited by short transit times and high concentrations of components derived from host-secretion fluids (Macfarlane and Macfarlane 1997; Booijink et al. 2007). Conversely, the transit time in the distal small intestine is substantially longer, providing a more favorable environment for microbial growth, which is reflected by the more dense microbial communities in this region of the GIT. Another environmental condition that contributes in microbial growth in the ileum is the neutral $\mathrm{pH}$ compared to more acidic $\mathrm{pH}$ values encountered higher up in the small intestine (Evans et al. 1988). Furthermore, as a result of ingestion of nutrients, the intestinal oxygenation is not static and the diverse anatomical physiology of the small intestine offers a range of oxygen microenvironments that favor local microbial niche formation (Espey 2013). As a consequence of these varying conditions, the small intestine harbors a variety of distinct niches, each containing a different microbial ecosystem that varies according to the location within the GIT. This is already demonstrated by the fact that the microbial density increases along the GIT, from $10^{1}-10^{4}$ microbial cells per gram of intestinal content in the stomach and duodenum, to $10^{4}-10^{8} \mathrm{cells} / \mathrm{g}$ in the jejunum and ileum (Booijink et al. 2007; Walter and Ley 2011). The presence of nutrients in combination with the reabsorption of bile acids occurring at the terminal ileum and the relatively longer residence time in comparison to the proximal small intestine not only favor microbial growth in the ileum but also create a dynamic environment where diet, host and microbiota are in a continuous interaction (Gerritsen et al. 2011).

Due to its poorly accessible location, there is only limited insight in the ecology of the small intestinal microbiota because sampling procedures consistently include invasive methodologies that may disturb the ecosystem (Booijink et al. 2007). Traditionally, most of the knowledge concerning the small intestinal microbiota has been derived from samples taken from sudden death victims or from ileal biopsies collected during surgical interventions (Wang et al. 2003; Hayashi et al. 2005; Wang et al. 2005; Ahmed et al. 2007; Willing et al. 2010). However, more recently, studies using extended catheters introduced via the oral route as well as effluent from ileostomy patients have generated much more knowledge on the human small intestinal ecosystem and its microbial inhabitants demonstrating its diversity in microbial niches along the length of the small intestine (Hartman et al. 2009; Booijink et al. 2010; Zoetendal et al. 2012; El Aidy, van den Bogert and Kleerebezem 2015).

In terms of the analysis of microbial diversity and functionality in the human small intestine, in vivo studies are the most relevant. However, due to limited accessibility to human ileal microbiota in vitro models could provide a means to study the small intestinal microbiota by allowing the implementation of reproducible and externally controlled conditions. So far, several in vitro model systems with different degrees of technical complexity and aiming to mimic the conditions encountered in the human GIT have been reported. Single-stage and multistage dynamic systems have been developed simulating all or part of the physiological parameters that could influence the GIT microbial community (Venema and van den Abbeele 2013). The majority of these in vitro simulators are representatives of the human large intestine and they have been successfully applied to mimic the local intestinal habitats. In contrast, the small intestine has been represented mainly by model systems mimicking the physiological parameters of the luminal environment which did generally not include the presence of microbiota (Minekus et al. 1995; Mainville, Arcand and Farnworth 2005; Havenaar et al. 2013) with the recent exception of a model system published by Cieplak and co-authors (Cieplak et al. 2018) which included a selected consortium of bacterial strains.

The aim of this study was to develop an in vitro model system for the human ileum, mimicking not only the physiological parameters of the ileal lumen but also its microbiota. The model was inoculated with different microbial inocula and the microbiota that established over time in the model was compared to the microbiota encountered in in vivo samples from the human small intestine.

\section{MATERIALS AND METHODS}

\section{In vitro ileum model development}

The development of the dynamic in vitro ileum model is based on the same concept as that of TIM-1 (TNO Intestinal Model -1) and TIM-2 (TNO Intestinal Model -2), the TNO (The Netherlands Organization for Applied Scientific Research) in vitro gastrointestinal models simulating the human stomach and small intestine, and the large intestine, respectively (Minekus et al. 1995; Minekus et al. 1999). The ileum in vitro model consists of two linked glass units with inner flexible walls (Fig. 1a).

Water of $37^{\circ} \mathrm{C}$ is pumped in the space between the glass units and the flexible wall at regular intervals, controlling the temperature of the units' content and yielding computer-controlled peristaltic movements by alternating compression and relaxation of the flexible walls, causing the content to be mixed and moved. The model contains an inlet system for delivering a defined bacterial growth medium (Fig. 1b) and an overflowsystem to control and maintain the luminal content at a set level. The model is equipped with a $\mathrm{pH}$ electrode monitoring $\mathrm{pH}$ over time (Fig. 1c), while $\mathrm{pH}$ is controlled by titration with $0.5 \mathrm{M}$ $\mathrm{NaOH}$ (Fig. 1d). Appropriate electrolyte and metabolite concentrations in the lumen are maintained with a dialysis system consisting of hollow fibers (molecular weight cut-off 10KDa; Fig. 1e) through which dialysis fluid (dialysate) is pumped. Due to the 


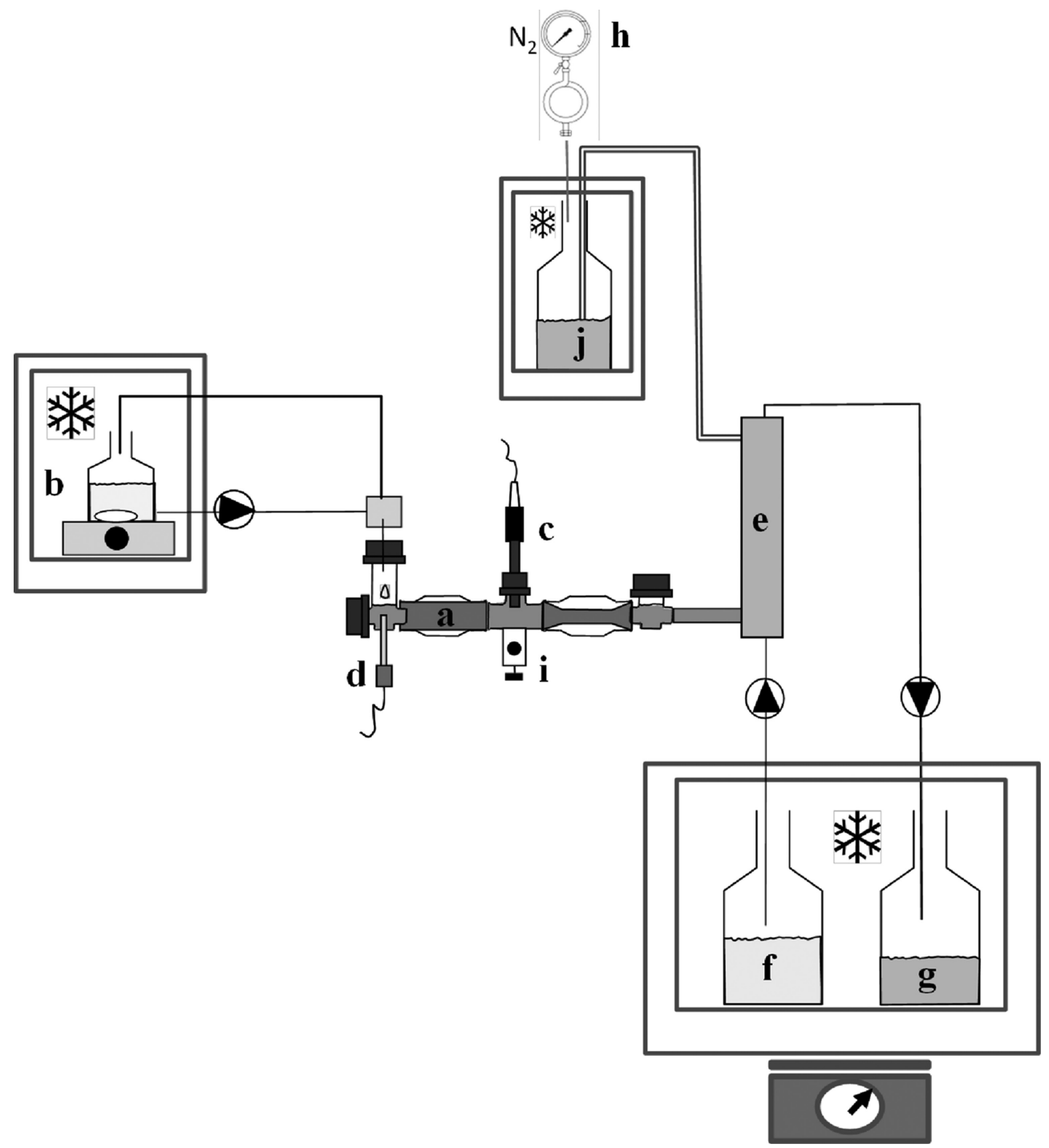

Figure 1. Schematic representation of the in vitro ileum model. (a) peristaltic compartments with flexible membranes; (b) defined medium in cooling chamber of $7^{\circ} \mathrm{C}$; (c) pH electrode; (d) $\mathrm{NaOH}$ port secretion; (e) hollow fiber membrane; (f) dialysis fluid in cooling chamber of $7^{\circ} \mathrm{C}$; the fluid flask is placed on a weighing scale (g) flask for metabolites and digestion products placed in cooling chamber of $7^{\circ} \mathrm{C}$; the flask is placed on a weighing scale; (h) nitrogen supply; (i) sampling port; (j) efflux collection flask in cooling chamber of $7^{\circ} \mathrm{C}$ flask.

constant flow of dialysis fluid (Fig. 1f) through the dialysis system, water and fermentation products are constantly removed (Fig. 1g) and product inhibition of enzymes due to accumulation of microbial metabolites is prevented. The in vitro system is flushed with nitrogen gas (Fig. 1h) in order to maintain anoxic intraluminal conditions The model is equipped with a sample port through which samples can be taken (Fig. 1i) and the luminal content excreted from the in vitro ileum is collected in a efflux vial (Fig. 1j).

The defined medium provided to the microbiota of the in vitro model was based on the medium described by Gibson et al (Gibson, Cummings and Macfarlane 1988) with modifications (Table 1), which simulates material passing the ileo-ceacal valve in humans (van Nuenen, Meyer and Venema 2003). The modifications of the medium deal with concentrations of each ingredient, which have been adjusted, based on experience with TIM-1 and in specific on experience with absorption of nutrients through dialysis. Dialysis fluid contained (per liter): $1.25 \mathrm{~g}$ $\mathrm{K}_{2} \mathrm{HPO}_{4} .3 \mathrm{H}_{2} \mathrm{O}, 2.25 \mathrm{~g} \mathrm{NaCl}, 0.0025 \mathrm{~g} \mathrm{FeSO}_{4} .7 \mathrm{H}_{2} \mathrm{O}$ and $2.025 \mathrm{~g}$ ox bile (Minekus et al. 1995). All medium components were provided by Tritium Microbiology (Eindhoven, the Netherlands).

Defined medium was pumped into the in vitro model for 14 consecutive days at a flow rate of $0.5 \mathrm{ml} / \mathrm{min}$ and dialysis fluid was pumped regularly through the hollow fibers at a flow rate of $1.1 \mathrm{ml} / \mathrm{min}$. The chosen flow rate of $0.5 \mathrm{ml} / \mathrm{min}$ corresponded to a total passage time of approximately $3.5 \mathrm{~h}$ (model internal volume of $100 \mathrm{ml}$ ), resembling a mean in vivo transit time which has been reported to be approximately $3-4 \mathrm{~h}$, based on pooled data of transit times measurements that employed different methodologies (Davis, Hardy and Fara 1986; Hung, Tsai and Lin 2006; McConnell, Fadda and Basit 2008).

The $\mathrm{pH}$ of the in vitro ileum model was set to 7.2, in accordance to in vivo measurements, which reported that terminal ileal $\mathrm{pH}$ in healthy individuals ranges from 7 to 7.5 postprandially (Evans et al. 1988; Gilbert et al. 1988), while pH is between 6.5 and 7 in a fasted state (Youngberg et al. 1987). 
Table 1. Composition of defined medium used in the experiments with the in vitro ileum model.

\begin{tabular}{lllll}
\hline Medium components & & & & \\
\hline Sugars $(\mathrm{g} / \mathrm{L})$ & Proteins $(\mathrm{g} / \mathrm{L})$ & $\mathrm{Salts}(\mathrm{g} / \mathrm{L})$ & Vitamins $(\mu \mathrm{g} / \mathrm{L})$ & Others $(\mathrm{g} / \mathrm{L})$ \\
\hline Starch (74.5) & Casein (70.0) & $\mathrm{K}_{2} \mathrm{HPO}_{4} .3 \mathrm{H}_{2} \mathrm{O}(4.7)$ & Menadion (1.5) & Tween-80 (50.3) \\
Pectin (8.9) & Bactopepton (70.0) & $\mathrm{NaCl}(8.4)$ & Biotin (3.0) & Bile (2.025) \\
Arabinogalactan (8.9) & & $\mathrm{CaCl}_{2} .2 \mathrm{H}_{2} \mathrm{O}(0.8)$ & Vitamin B12 (0.75) & Cysteine.HCl (0.3) \\
Amylopectin (8.9) & & $\mathrm{FeSO}_{4} .7 \mathrm{H}_{2} \mathrm{O}(0.01)$ & Pantathenate (15.0) & Haemine (0.02) \\
Xylan (8.9) & $\mathrm{MgSO}_{4}(0.7)$ & Nicotinamide (7.5) & \\
& & Para-aminobenzoic acid (7.5) & \\
& & Thiamine (6.0) & \\
\hline
\end{tabular}

\section{Experimental design}

We aimed to develop an in vitro model which simulates the physiological parameters of the human ileum together with its microbiota. This model system was validated with respect to its robustness using different microbial inocula, its reproducibility using multiple model units with similar inocula, its stability at different time points after inoculation, and its microbiota comparability to the in vivo situation. The microbiota composition and diversity as well as its dynamics were determined by phylogenetic profiling, while its functional stability was assessed by metabolic profiling.

At the start of each experiment, the in vitro model prototype was inoculated with microbiota originating from ileostomy effluent or feces, representing the proximal small and the large intestinal microbiota, respectively. The fecal inocula were obtained fresh at the day of the experiment and $1 \mathrm{~g}$ was mixed with $15 \mathrm{X}$ diluted defined medium in the anaerobic chamber prior to inoculation of the in vitro model. The frozen ileostomy effluent samples $(50 \mathrm{ml})$ were thawed at room temperature in the anaerobic chamber and processed similarly to the fecal inoculum. Duplicate units of the in vitro model were inoculated to assess reproducibility. For a period of 14 days defined medium was constantly pumped into the model system while luminal and dialysate samples $(1 \mathrm{ml}$ each) were taken starting $24 \mathrm{~h}$ after inoculation and every $24 \mathrm{~h}$ until the end of the experimental period. In addition, inoculum samples $(1 \mathrm{ml})$ were taken for microbial profiling. Samples were frozen in liquid nitrogen immediately after sampling and stored at $-80^{\circ} \mathrm{C}$ until analysis.

\section{Model inoculation with microbiota}

For this study, fecal and ileostomy effluent samples were used as inoculum for the model. Ileostomy effluent samples were used to run the in vitro model system in duplicate, while fecal samples were used as inoculum in three independent runs. A healthy ileostomist (female; $67 \mathrm{yrs}$ ) and a healthy individual (female; 34 yrs) signed a written informed consent, which was approved by the University Hospital Maastricht Ethical Committee and conducted in full accordance with principles of the 'Declaration of Helsinki' (52 ${ }^{\text {nd }}$ WMA General Assembly, Edinburgh, Scotland, October 2000), and donated ileostomy effluent and fecal material, respectively. The ileostomist had an intact small intestine with the exception of the terminal part of the ileum, which was removed during surgical removal of the colon, more than 5 years prior to the sampling period. The ileostomist did not report any complaints related to GIT functioning for more than 3 yrs prior to testing and was not following any treatment for GIT-related symptoms or specific dietary regime. Fresh ileostomy effluent was stored on dry ice, directly after collection at the ileostomist's residence and kept frozen during transport to the laboratory and prior to further use.

\section{DNA extraction}

Inocula and luminal samples collected daily from the in vitro model were thawed at room temperature and DNA was extracted from $250 \mu \mathrm{l}$ using the protocol of the Qiagen DNA extraction kit (Qiagen, Leiden, the Netherlands) as described before (Zoetendal et al. 2006). DNA purity and yield was assessed spectrophotometrically (Nanodrop ND-1000 spectrophotometer, Nanodrop Technologies, Wilmington, USA) and was adjusted to $20 \mathrm{ng} / \mu \mathrm{l}$ template for a subsequent 16S rRNA gene PCR amplification.

\section{Phylogenetic microarray analysis}

Phylogenetic profiling of the bacterial community was performed using the Human Intestinal Tract Chip (HITChip), a phylogenetic microarray that consists of 3699 oligonucleotide probes based on 16S rRNA gene sequences targeting over 1000 intestinal bacterial phylotypes (Rajilic-Stojanovic et al. 2009). The array probes are organized in two levels of phylogeny; i) the phylum level (Level 1), with the specification of Firmicutes down to Clostridium clusters and other classes, consisting in total of 23 groups and ii) the genus-like level (Level 2), consisting in total of 130 groups. Genus-level taxa distributed over several genera are termed 'et rel'. HITChip-based phylogenetic profiling was done as described before (Rajilic-Stojanovic et al. 2009).

In short, the 16S rRNA gene was amplified from 20ng of extracted DNA with the primers T7prom-Bact-27-for (5'-TGA ATT GTA ATA CGA CTC ACT ATA GGG GTT TGA TCC TGG CTC AG-3') and Uni-1492-rev (5'- CGG CTA CCT TGT TAC GAC$\left.3^{\prime}\right)$. PCR products were subsequently purified using the DNA Clean and Concentrator kit (Zymo Research Orange, USA) and quantity and purity were assessed spectrophotometrically using the Nanodrop. Purified 16S rRNA gene amplicons were in vitro transcribed from the T7 promoter into RNA with the Riboprobe System (Promega, La Jolla, USA) according to the manufacturer's instructions, using 500 ng of the T7-16S rRNA gene amplicon, rATP, gATP, rCTP, a 1:1 mix of rUTP and aminoallylrUTP (Ambion, Austin, Texas, USA). The in vitro transcribed RNA was further digested with RNAse-free DNAse (Qiagen, Hilden, Germany), purified with the RNeasy Mini-Elute Cleanup kit (Qiagen, Hilden, Germany) and quantified spectrophotometrically with Nanodrop. Subsequently, amino-allyl-modified nucleotides were labelled with Cy3 or Cy5 using CyDye, PostLabeling Reactive Dye (GE Healthcare, Little Chalfont, UK), which was followed by purification and quantification of the labeled RNA as described above. Hybridization of the labeled RNA 
was performed following fragmentation with 10X fragmentation reagent (Ambion, Austin, Texas, USA). Hybridization on 8X15K format microarrays (Agilent Technologies, Palo Alto, USA) was performed in a rotation oven (Agilent Technologies) at $62.5^{\circ} \mathrm{C}$ for $16 \mathrm{~h}$. Slides were subsequently washed and dried, followed by scanning. Data were extracted from the microarray images using the Agilent Feature Extraction software, versions 7.5-9.1 (http://www.agilent.com), data normalization was performed using a set of R-based scripts (http://www.r-projec t.org) while the further microarray analysis was performed in a custom-designed relational database which runs under the MySQL database management system (http://www.mysql.com) using a series of custom-made R scripts, as described previously (Rajilic-Stojanovic et al. 2009). Hierarchical clustering of probe profiles was carried out using Pearson's product moment correlation (Pearson's correlation) and Ward's minimum variance method.

\section{Quantitative PCR}

For quantification of total bacteria quantitative PCR (qPCR) analysis of total 16S rRNA genes was performed using the generic primers Bact-1369f (5'- CGG TGA CGT TCY CGG -3') and Prok1492r (5'- GGW TAC CTT GTT ACG ACT T-3') (Suzuki, Taylor and DeLong 2000). QPCR amplification and detection was performed with the iQ5 (Bio-rad Laboratories B.V., Veenendaal, the Netherlands) in a total reaction volume of $25 \mu \mathrm{l}$ containing $1 \mathrm{X}$ SYBR Green PCR Master Mix (Applied Biosystems, Foster City, USA), $100 \mathrm{nM}$ forward and reverse primers and $5 \mu \mathrm{l}$ of 10- and 100-fold diluted DNA, extracted as described above. The applied qPCR protocol consisted of denaturation at $95^{\circ} \mathrm{C}$ for $3 \mathrm{~min}$, followed by 40 cycles of $95^{\circ} \mathrm{C}(15 \mathrm{~s}), 56^{\circ} \mathrm{C}(30 \mathrm{~s}), 72^{\circ} \mathrm{C}(30 \mathrm{~s})$ and a final extension at $72^{\circ} \mathrm{C}$ for $5 \mathrm{~min}$. Signals were quantified by using the $16 \mathrm{~S}$ rRNA gene amplicon of E.coli Top10 strain as a standard. Data analysis was conducted with iQ5 Optical System Software version 1.1.

\section{Determination of Short Chain Fatty Acids}

Acetate, propionate, butyrate and lactate levels were determined in lumen and dialysate fluid samples obtained from the model system by High-Performance Liquid Chromatography (HPLC) as described previously (Stams et al. 1993). The Thermo Spectra HPLC system (Thermo Fischer Scientific, Breda, the Netherlands) was equipped with a Varian Metacarb $67 \mathrm{H}$ $300 X 6.5 \mathrm{~mm}$ column running with $0.005 \mathrm{M}$ sulphuric acid as eluent while the temperature was set to $60^{\circ} \mathrm{C}$. Standard stock solutions of all tested Short Chain Fatty Acids (SCFAs) were used to make calibration curves with which SCFAs in the tested samples were quantified.

\section{Statistical analysis}

The similarity of the total microbial composition based on the HITChip profiles was assessed by calculating the similarity indices based on the Pearson's correlation, which reflects the linear relationship between datasets. Principal Component Analysis (PCA) was used as implemented in the multivariate statistical software Canoco 4.5 for Windows (Leps and Smilauer 2003). PCA was performed on $\log _{10}$-transformed HITChip probe signalintensity profiles, focusing on inter-samples correlations, and diagrams were plotted by using CanoDraw.
The diversity of the microbial community assessed by HITChip analysis was expressed as Simpson's reciprocal diversity index (1/D) (Simpson 1949), which was calculated with the equation $\lambda=1 / \Sigma P i^{2}$, where $P i$ is the proportion of the ith taxon. The fraction of the total HITChip signal was used as a proxy for relative abundance for each taxon (Rajilic-Stojanovic, Smidt and de Vos 2007). Simpson's reciprocal diversity index takes into account both the number of taxa present in a sample and their abundance in the community. Therefore, a higher value of Simpson's reciprocal diversity index corresponds to a more diverse community.

To estimate saturation points reached by SCFA production in samples of fecal and ileostomy effluent origin in the studied time period, local polynomial curve fitting (loess; as implemented in the stats package of the R 2.15.3 statistical environment) was applied. The saturation point for each curve was identified as the local maximum where the gradient reached zero, and the time points following this equilibrium were reported for each curve where equilibrium was reached. The 95\% Gaussian confidence intervals are also shown for the fitted curves.

To compare the in vitro samples with in vivo samples in terms of composition and diversity, samples from the HITChip Atlas Database were employed, a data collection of thousands of microarray experiments from several independent studies (Nikkila and de Vos 2010; Lahti et al. 2014). The selected samples consisted of small intestinal, ileostomy effluent and fecal samples, all of them originating from healthy human individuals [data depository (Lahti 2019)]. The small intestinal samples were obtained using an intraluminal naso-ileal catheter (Zoetendal et al. 2012). These samples included a jejunal, two ileal and three terminal ileum samples (males; $24 \pm 4.5 \mathrm{yrs}$; individuals $\mathrm{M}-\mathrm{O}$ ). Ileostomy effluent samples and fecal samples were each collected from five subjects; 3 male, 2 female; $60.2 \pm 7.1 \mathrm{yrs}$; (Booijink et al. 2010); individuals C-G, and 3 female, 2 male; 41.4 \pm 13.2 yrs; (Qin et al. 2010); individuals H -L, respectively.

\section{RESULTS}

\section{Model development and evaluation of the in vitro microbiota}

To study the human small intestinal microbiota, an in vitro model for the human ileum was developed which was inoculated with two different microbial inoculates, derived from feces and ileostomy effluent, to subsequently evaluate the stability of the system and its microbiota but also to assess reproducibility in technical and biological levels. Within each run, the in vitro model was maintained under stable conditions regarding $\mathrm{pH}$, temperature, transit times and flow rates of the used substrate and dialysis fluids.

Robustness and technical reproducibility of in vitro ileal samples

To assess the robustness and reproducibility of the in vitro ileum model, it was inoculated with a fecal sample and subsequently the composition, diversity and population dynamics of microbiota were determined over time. Technical reproducibility was addressed by running two parallel module units (replicates A and B), inoculated with the same fecal inoculum. Using qPCR the development of the microbial community over time in the efflux samples obtained from the in vitro model was estimated. The total copy number of bacterial $16 \mathrm{~S}$ rRNA genes per $\mathrm{ml}$ ranged 
from $1.2 \times 10^{7}$ to $8.9 \times 10^{8}$ for all samples (Table S3, supporting Information) when inoculated with the fecal inoculum indicating that the total number of bacteria remained relatively stable, with a fluctuation more than 1 log over a period of 2 weeks after inoculation.

Phylogenetic profiling using the HITChip demonstrated that the microbiota composition in the in vitro model at the phylum/class level already became very distinct from the inoculum immediately after the start of the run (Fig. 2). In particular, typical facultative anaerobic bacteria belonging to the Proteobacteria phylum and the Bacilli (only for the replicate $\mathrm{A}$ ) class as well as Bacteroidetes increased, while strict anaerobic Firmicutes belonging to the Clostridium clusters IV and XIVa decreased. This dynamics pattern was highly similar for both units. During the run the microbiota stabilized after extended run-times with Pearson correlations between sampling days ranging from an average value at start of 0.40 to 0.98 at day 14 . Stability of the microbiota was reached after approximately 7 days, as concluded from the curve fitting approach on Pearson correlation indices (Fig. 2C). These stable microbiota profiles of both units were dominated by Bacteroidetes, Proteobacteria, Bacilli, Clostridium cluster XIVa and Actinobacteria (Fig. 2A).

Microbial diversity in samples obtained from the duplicate model units was found to decrease after inoculation reaching low Simpson's reciprocal diversity indices for both units A and $B$ at the end of the run (Fig. 3). The high Simpson's reciprocal diversity index of the original fecal samples (both inocula A and B) indicated that the diversity of the stabilized community residing within the units was drastically lower than that of the fecal inoculum.

Parallel to the microbial population dynamics, the production of SCFAs in the in vitro luminal samples indicated an increase of acetate, propionate and butyrate by two, ten and twenty fold, respectively (compared to inoculum). In contrast, lactate concentrations dropped to levels close to the lower detection limit shortly after inoculation (Table S1, Supporting Information). Analogous trends of SCFAs profiles were obtained for the dialysate samples (Table S2, Supporting Information). SCFA levels reached a steady state after day 10 concerning acetate and propionate while butyrate stabilized after nine days. Curve fitting analysis applied on the SCFA data indicated the same outcome of reaching stability within approximately 10 days (Fig. 4).

\section{Biological reproducibility of in vitro ileal samples}

To examine technical and biological reproducibility of the in vitro system, a replicate experimental run (encoded as C), was performed using a new fresh fecal inoculum from the same individual. Total microbial numbers in all replicate runs remained similar over time, with 16S rRNA copy gene numbers calculated with qPCR on average $1 \times 10^{8}$ copies per ml. In addition, similarity in microbial composition as well as dynamics was highly reproducible with Pearson's similarity indices higher than 0.8 measured after stabilization.

Inoculum samples of all replicate runs exhibited similar Simpson's reciprocal diversity indices, ranging from 130 to 173 index values, but differences in index values were observed at the end of the run. More specifically, samples of the replicate units (A and B) revealed a decrease in diversity levels (60 and 53, respectively), while samples of the replicate run (C) remained highly diverse (diversity index of 140) until day 14 (Fig. 3).

SCFA concentrations in both dialysis fluid and lumen samples were similar with acetate and propionate presenting the highest concentrations, and with stabilizing levels of SCFA levels after 9 to 10 days in each of the runs (Fig. 4; Tables S1 and S2, Supporting Information). This led to the conclusion that microbial communities within the in vitro model behaved similarly repeatedly, reaching stability at similar time intervals (after 7 to10 days), producing metabolites of comparable concentrations and comprising of similar microbial populations (Fig. 2A and Fig. 2B). Hence, 10 days after inoculation was determined as the start of the steady state community with Bacteroidetes, Proteobacteria, Bacilli, Clostridium cluster XIVa and Actinobacteria being the dominant groups. However, the variation in diversity between in vitro runs inoculated with different fecal inocula demonstrated the impact of the inoculum on the stabilized community and indicated that direct comparisons between runs can only be performed when the same inoculum is used.

\section{Stability and diversity of the in vitro ileum model with ileostomy effluent inoculum}

To determine the reproducibility of the selective conditions within the in vitro model, the microbiota composition, stability and diversity as well as their dynamics were determined using an ileostomy effluent sample, which harbors a different microbiota compared to feces, as the inoculum. The ileostomy effluent sample can be regarded as a representative sample for the proximal small intestine (Zoetendal et al. 2012). The duplicate units inoculated with this sample displayed increasing similarity for the microbial community patterns over time (as also it is shown by Pearson's correlation coefficient values) (Fig. 2C), reaching similar microbial communities towards the end of the experiment (Fig. 2B).

The population dynamics were similar to runs with fecal inocula as demonstrated with the similarity index that increased from 0.41 at start to 0.97 at day 14 for both units. Both replicates were characterized by increases in Proteobacteria, Bacteroidetes and Actinobacteria shortly after inoculation, whereas the Bacilli and Clostridium cluster XIVa groups decreased (Fig. 2B). In line with runs with the fecal inocula, the curve fitting approach on Pearson correlation indices indicated that stability of the microbiota was reached after approximately 7 days (Fig. 2C). However, in contrast to runs with the fecal inocula, the microbial diversity fluctuated around the average start index value of 54 during the whole run (Fig. 3). The stabilized microbial community in these ileostomy inoculated runs was predominated by Proteobacteria, Bacteroidetes, Bacilli, Clostridium clusters I and XIVa. Importantly, with exception of Clostridium cluster I, these groups were also dominating the model microbiota at steady state when fecal inocula were used, which demonstrates the robust selective conditions exerted by the in vitro model.

Metabolic profiling performed by HPLC showed for both lumen and dialysate samples that acetate and propionate were the most dominantly produced metabolites (Tables S1 and S2, Supporting Information). Remarkably and in contrast to runs using a fecal inoculum, lactate levels could be consistently detected in luminal samples at levels of $6.3 \mathrm{mM}$ almost immediately after inoculation. Notably, lactate could not be detected in the dialysate samples, suggesting that lactate present in the lumen is immediately consumed by members of the microbiota. Visual investigation of the fitted curves obtained by the measured SCFA concentrations indicated that no clear saturation point is reached for samples of ileostomy effluent inoculum, except for lactate, which seemed to stay at relatively stable levels 
(A)

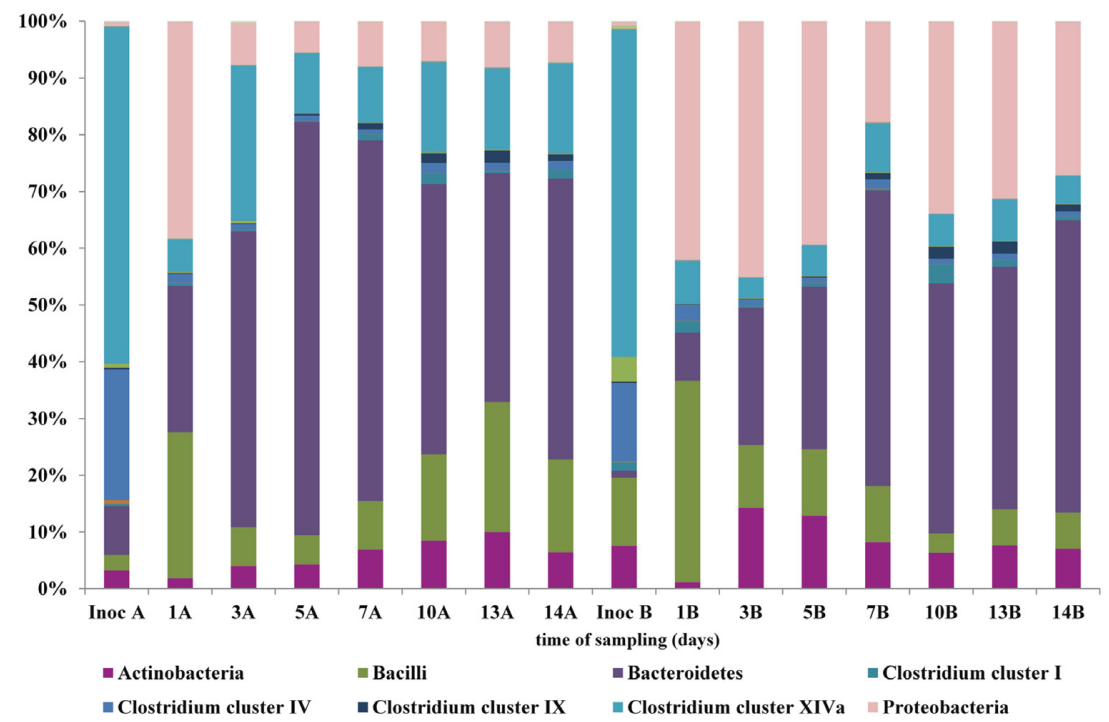

(B)

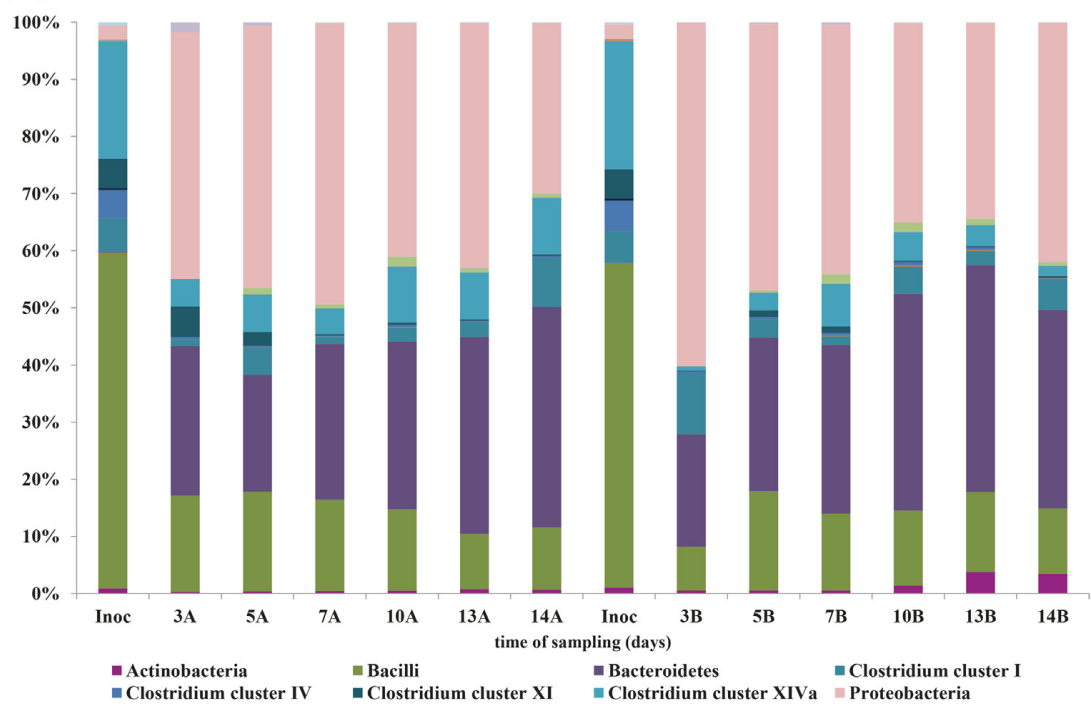

(C)
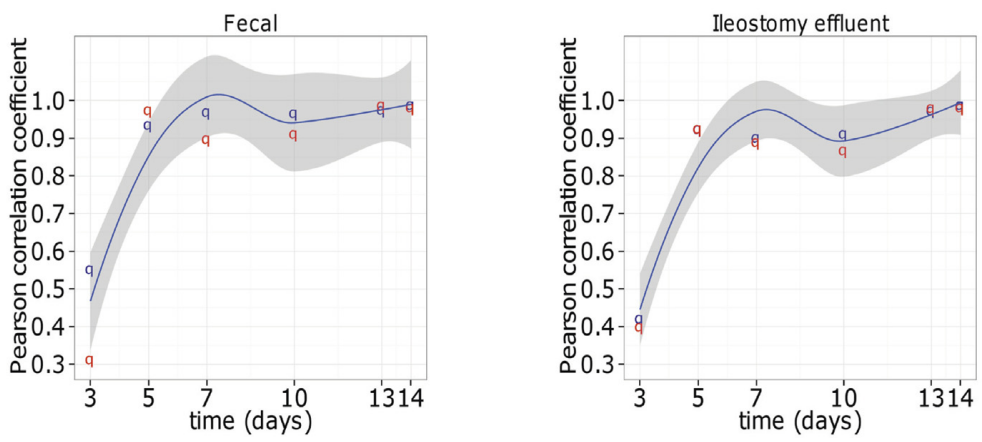

Figure 2. (A) Relative contributions of detected bacterial groups (phylum-like level) with HITChip analysis for in vitro samples of fecal inoculum, in duplicate (A and B). The time of sampling (in days) is indicated underneath the bars. Phylogenetic groups that contribute at least $2 \%$ to one of the profiles are indicated in the legend. (B) Relative contributions of detected bacterial groups (phylum-like level) with HITChip analysis for in vitro samples of ileostoma inoculum, in duplicate (A and B). The time of sampling (in days) is indicated under the bars. Phylogenetic groups that contribute at least $2 \%$ to one of the profiles are indicated in the legend. (C) Polynomial fitted curves of Pearson correlation coefficient derived from model samples of fecal (left) and ileostomy effluent inocula (right). Red and blue dots displayed on the curves correspond to samples of different time points derived from replicate model runs, unit A and unit B, respectively. The grey area depicted is the $95 \%$ confidence interval. 


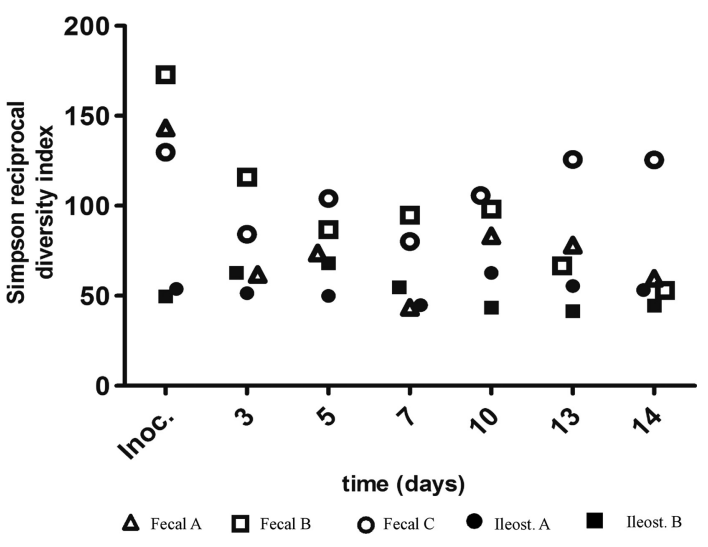

Figure 3. Bacterial diversity in samples of ileostomy and fecal inoculum performed in duplicate and triplicate, respectively. Diversity was estimated with Simpson's reciprocal diversity index for each time point.
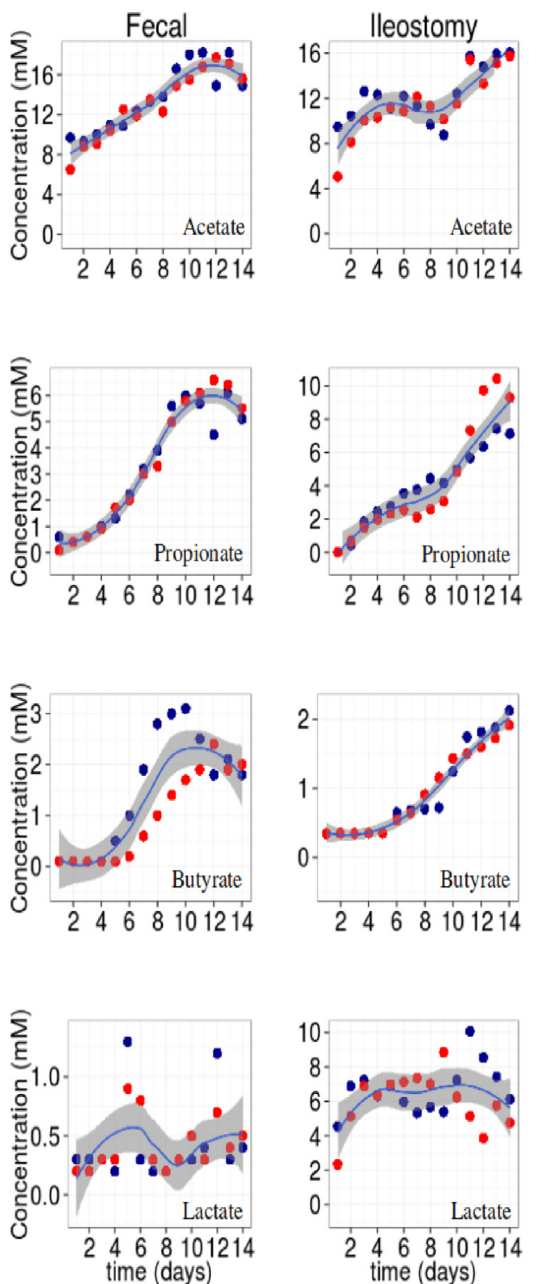

Figure 4. Polynomial fitted curves of SCFA concentrations obtained from luminal samples of fecal and ileostomy effluent origin. Acetate, propionate, butyrate and lactate concentrations are depicted in separate curves for both fecal and ileostomy effluent samples, while blue and red dots correspond to samples obtained from replicate model units (unit A and B, respectively). The $95 \%$ confidence interval is depicted by the grey area. throughout the experiment (Fig. 4), indicating that in contrast to compositional stability, no functional stability was reached during the run.

In conclusion, the in vitro ileum model system selected for similar steady state microbial communities that were reached 10 days after inoculation independent of the substantially different starting inocula used, which clearly indicates the strong selective physico-chemical conditions created within the in vitro model. However, functional stability was only reached using the fecal inocula, which indicated that fecal samples are more suitable to obtain steady state communities for the in vitro ileum model.

In vitro ileal microbiota versus in vivo intestinal microbiota

To evaluate to what extent the in vitro model enabled the selection of a microbiota that resembles the community that is encountered in the human ileum in vivo, the bacterial composition of the steady state in vitro ileum model of both inocula (fecal/ileostomy effluent) was compared to that of five fecal, five ileostomy effluent and six small intestinal samples, that were obtained from the HITChip Atlas database (Booijink et al. 2010; Nikkila and de Vos 2010; Zoetendal et al. 2012; Lahti et al. 2014). Cluster analysis of these diverse microbial profiles resulted in grouping of the in vitro microbiota profiles with those of the in vivo ileal samples (Fig. 5A), which appeared to be independent of the inoculum used. PCA showed a clear separation between the ileostomy effluent, the fecal and the in vitro model samples (Fig. 5B).

In line with previous observations (Zoetendal et al. 2012), ileostomy effluent samples clustered closely to jejunal and ileal samples, while terminal ileal samples were similar to feces. Notably, in vitro model samples of both fecal and ileostomy effluent inoculum were positioned close to in vivo ileal samples. Moreover, comparison of Simpson reciprocal diversity indices of microbial diversity of ileal, ileostomy effluent and fecal samples (Fig. S1, Supporting Information) showed that ileal and ileostomy samples possessed less complex microbiota than fecal samples with average diversity indices of 49 and 35, respectively, that are similar to that of in vitro model samples of ileostomy inoculum (diversity index value of approximately 50).

With exception of one fecal sample (run C), the diversity of the steady state communities had Simpson's reciprocal diversity indices of 50-60, which is also close to that observed for in vivo ileum samples (Fig. S1, Supporting Information). Overall, this microbiota comparison revealed that the in vitro model samples resembled in vivo ileal samples in terms of bacterial composition and diversity.

To determine whether specific groups could be identified as signature bacteria for in vivo and in vitro ileum, comparative analysis of the microbiota between these samples was done at phylum and genus-like level. The bacterial composition of ileostomy effluent samples (subjects C, D, E, F and G) was dominated by Bacilli, Clostridium cluster IX and XIVa and several gamma Proteobacteria, displaying high similarity with microbial composition profiles obtained from jejunal (subject N) and one of the two ileal samples from subject M (Zoetendal et al. 2012). Bacteroidetes, Clostridium cluster XIVa and Proteobacteria were among the dominant groups in the other ileal sample of subject $\mathrm{M}$ and terminal ileal samples (subjects $\mathrm{N}$ and $\mathrm{O}$ ), whereas fecal samples of different subjects (H, I, J, K and L) were dominated by Clostridium clusters IV and XIVa and Bacteroidetes. Likewise, 
(A)

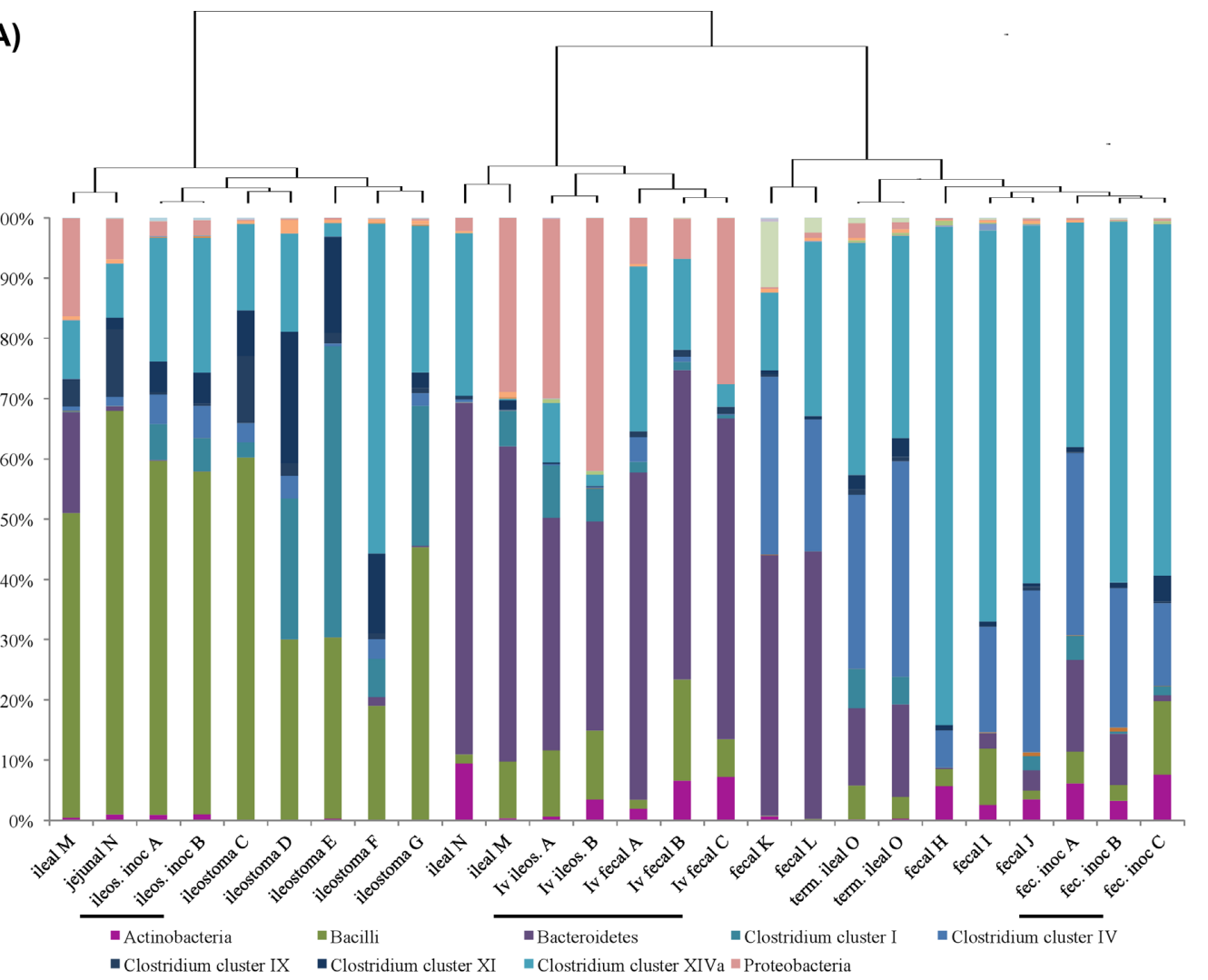

(B)

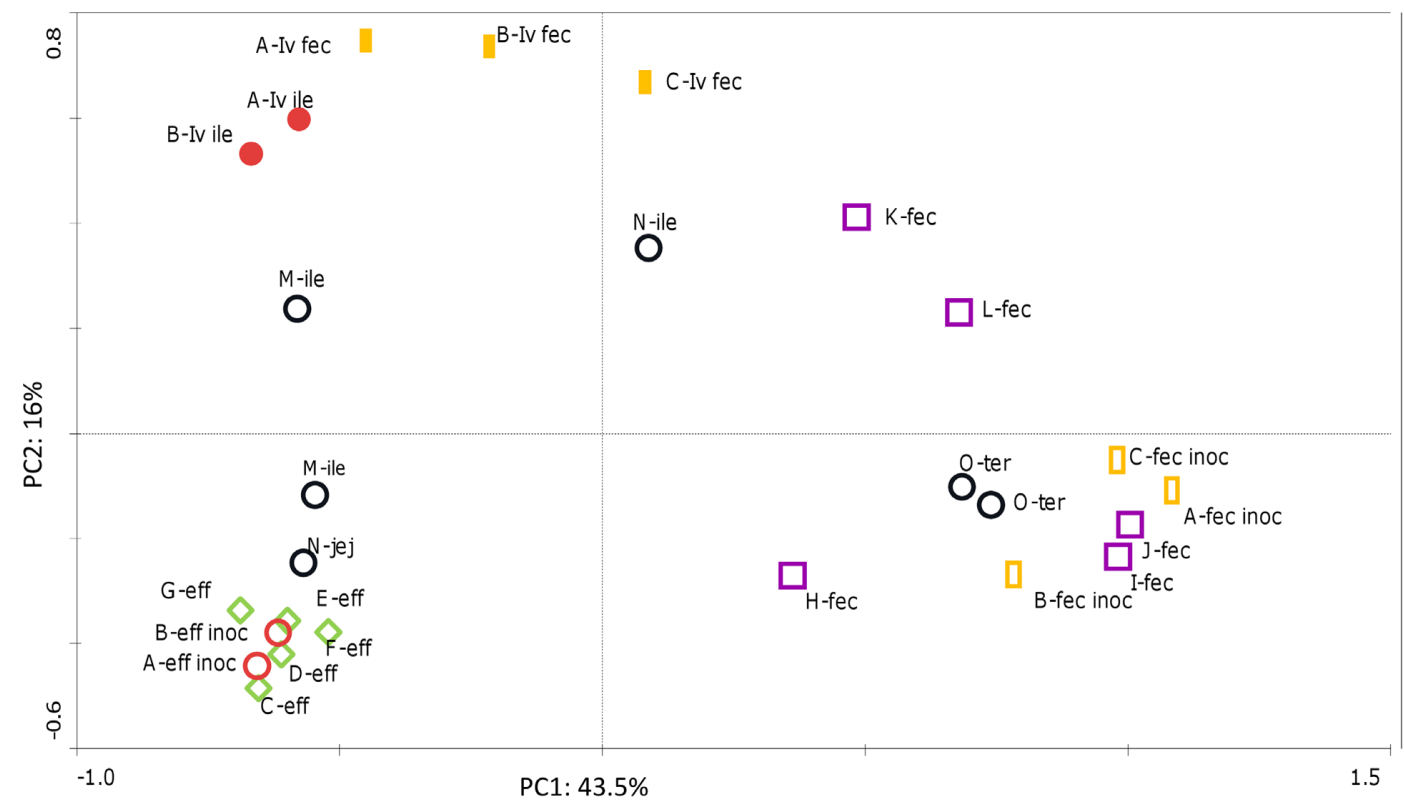

O Ileal \& jejunal $\square$ fecal $\diamond$ ileostomy $\square$ fecal model inoc $\bigcirc$ Ileos. model inoc $\square$ Iv fecal $\bigcirc$ Iv ileostomy

Figure 5. (A) Relative contribution of bacterial groups (phylum-like level) present in samples derived from small intestine and feces of three and five healthy individuals, respectively, those from ileostoma of five healthy ileostomists and those from the in vitro ileum model, inoculated with ileostoma and feces. The ileostomy (ileos.) effluent and the fecal (fec.) inocula are shown as well. These and the in vitro (Iv) samples are underlined. The tree represents Pearson clustering of HITChip probe profiles. (B) PCA of microbiota based on HITChip probe signal intensities. Percentage values at the axes indicate contribution of the principal components to the explanation of total variance in the data set. A-B encode the two identical model units; C-O encode healthy subjects; eff, fec, jej, ile, ter, eff inoc, fec inoc, Iv ile, Iv fec encode ileostomy effluent, fecal, jejunal, ileal, terminal ileal, ileostomy effluent inoculum, fecal inoculum, in vitro ileostomy, in vitro fecal respectively. 
relative abundances of microbial profiles of steady state in vitro samples indicated the groups of Proteobacteria, Bacteroidetes, Bacilli and Clostridium cluster XIVa as the dominant populations, independent of inoculum (Fig. 2A and B). On a higher resolution taxonomic level, the genus-like bacterial groups obtained from in vivo and in vitro samples showed differences in abundance, taken into account the inter-individual variability observed in the in vivo samples. Among the phylogenetic groups contributing $\geq 1 \%$ to both in vivo and in vitro samples, genus-like groups belonging to phylum Bacteroidetes were detected in all samples, with Bacteroides fragilis et rel. being a typical group selected in the in vitro system (Table 2).

Furthermore, in vivo small intestinal samples exhibited dominance in Streptococcus-like groups, with the jejunal sample reaching approximately $60 \%$ relative contribution of the above groups (not shown). In contrast, none of these Bacilli members were detected in considerable amounts in vitro. Members of Proteobacteria were detected mainly in in vitro samples, independent of inoculum, while Faecalibacterium prausnitzii, a group contributing more than $25 \%$ to the total genus-like taxa in in vivo small intestinal samples, was hardly selected in vitro. Clostridia and Parabacteroides distasonis et rel. remained consistent over in vivo and in vitro samples. In conclusion, Bacteroides fragilis et rel., belonging to Bacteroidetes, were consistently found in vitro, while streptococci and Faecalibacterium prausnitzii et rel. of the diverse group of Firmicutes were hardly detected in vitro. Despite the clear congruency at a lower resolution phylogenetic level, there is less overlap between in vivo and in vitro microbial communities in the higher resolution phylogenetic level, indicative of the selectiveness of the in vitro model for specific microbial habitats.

\section{DISCUSSION}

In this study, we report the development of a dynamic in vitro model for the human ileum and the assessment of its microbiota composition and activity using culture-independent 16S rRNA gene-based techniques and SCFA profiling. Previously, several in vitro model systems simulating the human GIT have been developed in an attempt to simulate the entire or part of the physico-chemical parameters of the luminal environment in the human GIT, which influence the microbiota composition and its metabolic activity (Gibson, Cummings and Macfarlane 1988; Molly, Woestyne and Verstraete 1993; Minekus et al. 1999). Nevertheless, the vast majority of the microbial models solely target the distal GIT leaving the small intestine and its microbial community unexplored. In a recent publication, a low volume in vitro model of the small intestine has been described, where a bacterial consortium of seven strains have been included simulating the ileal microbiota (Cieplak et al. 2018). The in vitro model system for the human ileum presented here attempts to simulate in vitro the ileal microbial ecosystem and demonstrated that the microbial populations residing in the human ileum could be selected in the in vitro model presented allowing their in vitro study.

The in vitro ileum model is a single stage fermenter simulating physiological parameters of the luminal environment in the ileum, including peristaltic movements of the luminal content through the system and uptake of the microbial metabolites and water. The microbial community residing in the in vitro model reached a compositionally steady state after 10 days with community densities of approximately $10^{8}$ rRNA gene copies per $\mathrm{ml}$, which is in good agreement with in vivo measurements in the human ileum, containing $10^{7}$ to $10^{8}$ bacterial cells of luminal content (Booijink et al. 2007). However, it is important to realize that the small intestine is very dynamic with peak loads of substrates via the diet and hence, bacterial composition and numbers may fluctuate during the day. Such variations have been observed in ileostomists (Booijink et al. 2010; Van den Bogert 2013) and it is likely that such fluctuations also occur in the distal small intestine of subjects with a colon. Techni$\mathrm{cal}$ and biological reproducibility of the microbiota development in the in vitro model were also assessed, showing that independent of the inoculum used (fecal or ileostomy effluent) a similar microbiota succeeded during the operation of the model. In continuous culture systems such as chemostat cultivation setups, a single culture of a specific microorganism is considered to reach a steady state after a time period that equals five to seven fermenter-volume changes. This would imply that the in vitro ileum model could reach steady state after less than $24 \mathrm{~h}$, when inoculated with a single culture ( $24 \mathrm{~h}$ corresponds to approximately seven volume changes). The time required to achieve stabilization using more complex microbial ecosystems appears to be less predictable, and may also vary more between different ecosystems, depending on the microorganisms present in the inoculum used. In an in vitro model for the human colon, designated SHIME, a stabilization period of 2 weeks was reported to be required to allow the microbiota to adapt to the in vitro environment (Van den Abbeele et al. 2010). Analogously, another in vitro three/stage model for the human colon, described by Spratt and colleagues, reached steady state after 12 to 14 days (Spratt et al. 2005). These adaptation times are similar to the ones observed in our study and may suggest that the time-constraint needed for stability is dominantly determined by the ecosystem complexity rather than by the transfer rate. These factors that intrinsically may relate to ecosystem complexity are varying growth kinetics between microbes, cross-feeding variability in adaptation time of different populations, all of which are common in the small and large intestine.

Upon steady state establishment, the in vitro microbial communities reached microbial profiles distinct of their inocula. Simpson's reciprocal diversity indices of in vitro samples from fecal inocula were lower at steady state than that of their inocula, while in vitro samples of ileostomy inocula had similar diversity indices to that of their inocula. Shannon's diversity index was estimated as well, confirming Simpson's reciprocal diversity index findings (data not shown). The initial adaptation of the inoculum in the in vitro model, which introduced shifts in the composition, affecting the relative abundance of several microbial groups, has been also observed by Rajilic-Stojanovic and colleagues (Rajilic-Stojanovic et al. 2010) and Van den Abbeele and colleagues (Van den Abbeele et al. 2010), in their studies of colonic in vitro microbiota in the TIM-2 model and SHIME in vitro model, respectively. Adaptation of the microbiota to the in vitro physiological conditions and wash-out of dead cells present in the initial inoculum might partly explain the decrease of microbiota diversity during the model operation. In addition, the selective conditions of the in vitro model, such as the media components, are not likely to fully mimic in vivo intestinal conditions and may therefore be incompatible to certain microbial groups.

SCFAs produced by microbial groups in in vitro samples revealed low concentrations of measured acids, in comparison to levels that are typically observed in in vivo ileostomy effluent and fecal samples (Cummings 1995; Zoetendal et al. 2012). Independent studies of SCFA concentrations in luminal colonic content have been reported to be between 30 and $70 \mathrm{mM}$, with relative proportions of acetate (40 to $70 \mathrm{mM}$ ), propionate and 
Table 2. Abundance of genus-like bacterial groups (mean $\pm \mathrm{SD}$ ) detected in in vivo and in vitro ileum samples using the HITChip microarray. In vitro samples are indicated in the table as Mean Iv fecal and Mean Iv ileos. Groups contributing at least $1 \%$ to the bacterial profile of a given sample are shown and those that contribute above $1 \%$ in a particular sample are indicated in bold.

\begin{tabular}{|c|c|c|c|c|}
\hline Phylum/Order & Genus-like phylogenetic group & $\begin{array}{l}\text { Mean ileal } \\
\text { samples }\end{array}$ & $\begin{array}{l}\text { Mean Iv fecal } \\
\text { samples }\end{array}$ & $\begin{array}{c}\text { Mean Iv ileos. } \\
\text { samples }\end{array}$ \\
\hline Actinobacteria & Bifidobacterium & $0.09 \pm 1.96$ & $5.09 \pm 1.35$ & $1.88 \pm 0.01$ \\
\hline Bacteroidetes & Bacteroides stercoris et rel. & $0.20 \pm 4.22$ & $2.57 \pm 9.32$ & $2.75 \pm 2.17$ \\
\hline Bacteroidetes & Bacteroides vulgatus et rel. & $2.93 \pm 2.09$ & $0.81 \pm 1.94$ & $0.51 \pm 4.07$ \\
\hline Bacteroidetes & Parabacteroides distasonis et rel. & $2.01 \pm 3.01$ & $3.44 \pm 3.10$ & $1.16 \pm 0.40$ \\
\hline Bacteroidetes & Prevotella melaninogenica et rel. & $3.23 \pm 1.55$ & $0.01 \pm 1.09$ & $0.02 \pm 0.26$ \\
\hline Bacteroidetes & Prevotella tannerae et rel. & $0.92 \pm 0.99$ & $1.65 \pm 0.73$ & $0.68 \pm 1.32$ \\
\hline Bacteroidetes & Tannerella et rel. & $0.45 \pm 8.71$ & $1.06 \pm 0.73$ & $0.64 \pm 0.12$ \\
\hline Bacteroidetes & Allistipes et rel. & $2.83 \pm 5.36$ & $2.61 \pm 2.93$ & $0.80 \pm 1.91$ \\
\hline Bacteroidetes & Bacteroides fragilis et rel. & $0.13 \pm 1.50$ & $18.31 \pm 1.41$ & $19.54 \pm 0.16$ \\
\hline Bacteroidetes & Bacteroides intestinalis et rel. & $0.62 \pm 3.33$ & $4.99 \pm 0.63$ & $3.00 \pm 2.31$ \\
\hline Bacteroidetes & Bacteroides ovatus et rel. & $0.30 \pm 0.84$ & $6.94 \pm 0.01$ & $1.05 \pm 0.08$ \\
\hline Bacteroidetes & Bacteroides splachnicus et rel. & $0.44 \pm 3.23$ & $2.71 \pm 0.04$ & $0.41 \pm 0.01$ \\
\hline Bacilli & Streptococcus bovis et rel. & $2.18 \pm 2.39$ & $0.49 \pm 2.17$ & $0.04 \pm 1.99$ \\
\hline Bacilli & Streptococcus mitis et rel. & $2.42 \pm 8.26$ & $0.02 \pm 0.73$ & $0.03 \pm 2.26$ \\
\hline Clostridium cluster I & Clostridia & $6.50 \pm 0.42$ & $1.23 \pm 0.01$ & $7.08 \pm 0.01$ \\
\hline Clostridium cluster IV & Faecalibacterium prausnitzii et rel. & $25.37 \pm 0.40$ & $0.06 \pm 0.28$ & $0.00 \pm 0.12$ \\
\hline Clostridium cluster XI & Clostridium difficile et rel. & $2.30 \pm 2.43$ & $0.03 \pm 2.97$ & $0.12 \pm 1.73$ \\
\hline Clostridium cluster XIVa & Bryantella formatexigens et rel. & $2.61 \pm 0.58$ & $1.11 \pm 0.17$ & $0.18 \pm 2.67$ \\
\hline Clostridium cluster XIVa & Clostridium nexile et rel. & $5.89 \pm 4.39$ & $0.06 \pm 1.93$ & $0.01 \pm 0.94$ \\
\hline Clostridium cluster XIVa & Clostridium symbiosum et rel. & $2.30 \pm 8.03$ & $3.25 \pm 0.00$ & $2.30 \pm 0.01$ \\
\hline Clostridium cluster XIVa & Dorea forminigenerans et rel. & $5.05 \pm 2.62$ & $4.61 \pm 1.26$ & $0.06 \pm 0.69$ \\
\hline Clostridium cluster XIVa & Eubacterium hallii et rel. & $1.13 \pm 0.97$ & $0.02 \pm 1.00$ & $0.01 \pm 0.50$ \\
\hline Clostridium cluster XIVa & Eubacterium rectale et rel. & $1.95 \pm 1.84$ & $0.23 \pm 0.62$ & $0.09 \pm 0.10$ \\
\hline Clostridium cluster XIVa & Lachnospira pectinoschiza et rel. & $1.93 \pm 9.24$ & $0.25 \pm 0.47$ & $1.98 \pm 0.04$ \\
\hline Clostridium cluster XIVa & Ruminococcus obeum et rel. & $4.34 \pm 5.17$ & $0.82 \pm 0.01$ & $0.17 \pm 0.01$ \\
\hline Proteobacteria & Escherichia et rel. & $0.00 \pm 13.25$ & $0.65 \pm 0.01$ & $3.51 \pm 0.03$ \\
\hline Proteobacteria & Klebsiella pneumoniae et rel. & $0.05 \pm 2.11$ & $2.97 \pm 0.44$ & $10.79 \pm 0.13$ \\
\hline Proteobacteria & Pseudomonas & $0.00 \pm 2.40$ & $0.79 \pm 0.00$ & $2.34 \pm 0.00$ \\
\hline Proteobacteria & Xanthomonadaceae & $1.09 \pm 2.77$ & $1.43 \pm 0.66$ & $0.78 \pm 0.47$ \\
\hline Proteobacteria & Yersinia et rel. & $0.00 \pm 0.29$ & $0.54 \pm 0.46$ & $5.26 \pm 4.06$ \\
\hline
\end{tabular}

butyrate (10 to $30 \mathrm{mM}$ each) being approximately 3:1:1 (Cummings 1995; Schwiertz et al. 2010). Likewise, SCFA concentration in ileostomy effluent has been quantified and considerable concentrations of acetate, propionate and butyrate were measured (acetate, propionate and butyrate mean concentrations of 75,3 and $17.5 \mathrm{mM}$, respectively), comparable to some extent to that of fecal samples (Zoetendal et al. 2012). The levels determined in the in vitro model described here, independent of inoculum, revealed a ratio of acetate, propionate and butyrate of approximately 6:3:1 indicating that in vitro microbiota show metabolic activity with acetate and propionate being the main metabolites, comparable proportionally to that of in vivo conditions. It is noteworthy to mention that the continuous flow of digested food in the in vitro system provides nutrients steadily throughout every experimental run, which is different when compared to in vivo. In an in vivo situation, peaks of food bolus unevenly distributed in time take place, which may lead to peaks of higher substrate level as well and therefore, explain the lower SCFA values measured in vitro. Functional stability in the in vitro model was only reached when fecal inoculum was used which could be attributed to the fact that certain functional groups within the in vitro ecosystem are not present in ileostomy effluent inoculum.

PCA analysis on compositional data obtained from samples of ileostomy effluent, jejunum, ileum, colon and the in vitro ileum model showed clustering of all in vitro samples with ileum samples obtained from healthy human volunteers, independent of the inoculum used to start the in vitro model. Ileostomy effluent samples appear to cluster separately and seem more similar to samples obtained from the proximal small intestine of healthy human volunteers, as has been reported before (Zoetendal et al. 2012). These findings suggest that the in vitro model microbiota cluster closest to two ileal samples from healthy individuals as compared to samples taken from the other regions of the intestinal tract. However, when analyzed at higher resolution the in vitro model microbiota still appears quite distinct from that encountered in the ileum in vivo.

In conclusion, an in vitro model for the human ileum has been developed with the aim to enable studies of its microbiota. Here, we demonstrate that the ileum microbiota can be adequately reproduced using the in vitro model, indicating that the model can serve as a useful tool for the determination of the impact of various physico-chemical or nutrient factors on the microbiota, which is not easily achieved in vivo. Examples may be the modulation of ileal transit time, specific responsiveness to certain nutritional components or drugs, as well as peak loading of substrates. Although a stable ileum-like ecosystem can be obtained with ileostomy effluent and feces as inocula, we will in subsequent studies use fecal inocula since these enabled the establishment of a functionally stable community faster. Overall, the model presented here may enable the deciphering of microbiota-environment relationships that are driving the microbial composition and activity within this highly relevant region of the human GIT, which may fuel future dietary or 
pharmaceutical interventions using rationalized, model-study based approaches.

\section{SUPPLEMENTARY DATA}

Supplementary data are available at FEMSEC online.

Conflicts of interest. None of the authors in this article have conflicts of interest.

\section{REFERENCES}

Ahmed S, Macfarlane GT, Fite A et al. Mucosa-associated bacterial diversity in relation to human terminal ileum and colonic biopsy samples. Appl Environ Microbiol 2007;73:7435-42.

Booijink C, Zoetendal EG, Kleerebezem M et al. Microbial communities in the human small intestine: coupling diversity to metagenomics. Future Microbiol 2007;2:285-95.

Booijink C, El-Aidy S, Rajilic-Stojanovic M et al. High temporal and inter-individual variation detected in the human ileal microbiota. Environ Microbiol 2010;12:3213-27.

Cieplak T, Wiese M, Nielsen $\mathrm{S}$ et al. The smallest intestine (TSI)-a low volume in vitro model of the small intestine with increased throughput. FEMS Microbiol Lett 2018;365 10.1093/femsle/fny231.

Cummings JH. Human colonic bacteria: role in nutritional physiology and pathology. Shortchain Fatty Acids Gibson GR, Macfarlane GT (eds). Boca Paton, FL: CRC Press, 1995.

Davis SS, Hardy JG, Fara JW. Transit of pharmacuetical dosage forms through the small-intestine. Gut 1986;27:886-92.

El Aidy S, van den Bogert B, Kleerebezem M. The small intestine microbiota, nutritional modulation and relevance for health. Curr Opin Biotechnol 2015;32:14-20.

Espey MG. Role of oxygen gradients in shaping redox relationships between the human intestine and its microbiota. Free radic biol med 2013;55:130-40.

Evans DF, Pye G, Bramley R et al. Measurement of gastrointestinal $\mathrm{pH}$ profiles in normal ambulant human-subjects. Gut 1988;29:1035-41.

Feng Q Chen WD, Wang YD. Gut Microbiota: an integral moderator in health and disease. Fronti Microbiol 2018;9:151.

Gerritsen J, Smidt H, Rijkers GT et al. Intestinal microbiota in human health and disease: the impact of probiotics. Genes and Nutrition 2011;6:209-40.

Gibson GR, Cummings JH, Macfarlane GT. Use of a 3-stage continuous culture system to study the effect of mucin on dissimilatory sulfate reduction and methanogenesis by mixed populations of human gut bacteria. Appl Environ Microbiol 1988;54:2750-5.

Gilbert J, Kelleher J, Littlewood JM et al. Ileal pH in cystic-fibrosis. Scand J Gastroenterol 1988;23:132-4.

Hartman AL, Lough DM, Barupal DK et al. Human gut microbiome adopts an alternative state following small bowel transplantation. PNAS 2009;106:17187-92.

Havenaar R, Anneveld B, Hanff LM et al. In vitro gastrointestinal model (TIM) with predictive power, even for infants and children? Int J Pharm 2013;457:327-32.

Hayashi $\mathrm{H}$, Takahashi R, Nishi $\mathrm{T}$ et al. Molecular analysis of jejunal, ileal, caecal and recto-sigmoidal human colonic microbiota using 16S rRNA gene libraries and terminal restriction fragment length polymorphism. J Med Microbiol 2005;54:1093101.

Hung GU, Tsai CC, Lin WY. Development of a new method for small bowel transit study. Ann Nucl Med 2006;20:387-92.
Kararli TT. Comparison of the gastrointestinal anatomy, physiology, and biochemistry of humans and commonly used laboratory-animals. Biopharm Drug Dispos 1995;16:351-80.

Lahti L. DataFile. 2019.DOI:106084/m9.figshare.7577654.v1.

Lahti L, Salojarvi J, Salonen A et al. Tipping elements in the human intestinal ecosystem. Nat Commun 2014;5:10.

Leps J, Smilauer P. Multivariate Analysis of Ecological Data using CANOCO. Cambridge, UK: Cambridge University Press, 2003.

Macfarlane GT, Macfarlane S. Human colonic microbiota: Ecology, physiology and metabolic potential of intestinal bacteria. Scand J Gastroenterol 1997;32:3-9.

Mainville I, Arcand Y, Farnworth ER. A dynamic model that simulates the human upper gastrointestinal tract for the study of probiotics. Int J Food Microbiol 2005;99:287-96.

McConnell EL, Fadda HM, Basit AW. Gut instincts: explorations in intestinal physiology and drug delivery. Int $J$ Pharm 2008;364:213-26.

Minekus M, Marteau P, Havenaar $\mathrm{R}$ et al. A multicompartmental dynamic computer-controlled model simulating the stomach and small-intestine. Atla-Alternatives Lab Anim 1995;23:197-209.

Minekus M, Smeets-Peeters M, Bernalier A et al. A computercontrolled system to simulate conditions of the large intestine with peristaltic mixing, water absorption and absorption of fermentation products. Appl Microbiol Biotechnol 1999;53:108-14.

Molly K, Woestyne MV, Verstraete W. Development of a 5step multichamber reactor as a simulation of the human intestinal microbial ecosystem. Appl Microbiol Biotechnol 1993;39:254-8.

Nikkila J, de Vos WM. Advanced approaches to characterize the human intestinal microbiota by computational metaanalysis. $j$ clin gastroenterol 2010;44:s2-s5.

Ottman N, Smidt H, de Vos WM et al. The function of our microbiota: who is out there and what do they do? Front Cell Infect Microbiol 2012;2.

Qin JJ, Li RQ Raes $\mathrm{J}$ et al. A human gut microbial gene catalogue established by metagenomic sequencing. Nature 2010;464:59-U70.

Rajilic-Stojanovic M, Smidt H, de Vos WM. Diversity of the human gastrointestinal tract microbiota revisited. Environ Microbiol 2007;9:2125-36.

Rajilic-Stojanovic M, Maathuis A, Heilig $\mathrm{H}$ et al. Evaluating the microbial diversity of an in vitro model of the human large intestine by phylogenetic microarray analysis. MicrobiologySgm 2010;156:3270-81.

Rajilic-Stojanovic M, Heilig H, Molenaar D et al. Development and application of the human intestinal tract chip, a phylogenetic microarray: analysis of universally conserved phylotypes in the abundant microbiota of young and elderly adults. Environ Microbiol 2009;11:1736-51.

Schwiertz A, Taras D, Schafer K et al. Microbiota and SCFA in lean and overweight healthy subjects. Obesity 2010;18:190-5.

Sekirov I, Russell SL, Antunes LCM et al. Gut microbiota in health and disease. Physiol Rev 2010;90:859-904.

Simpson EH. Measurement of diversity. Nature 1949;163:688.

Spratt P, Nicolella C, Pyle DL. An engineering model of the human colon. Food Bioprod Process 2005;83:147-57.

Stams AJM, Van Dijk JB, Dijkema C et al. Growth of syntrophic propionate-oxidizing bacteria with fumarate in the absence of methanogenic bacteria. Appl Environ Microbiol 1993;59:1114-9. 
Sundin OH, Mendoza-Ladd A, Zeng MT et al. The human jejunum has an endogenous microbiota that differs from those in the oral cavity and colon. BMC Microbiol 2017;17:17.

Suzuki MT, Taylor LT, DeLong EF. Quantitative analysis of smallsubunit rRNA genes in mixed microbial populations via 5'nuclease assays. Appl Environ Microbiol 2000;66:4605-14.

Van den Abbeele P, Grootaert C, Marzorati M et al. Microbial Community Development in a Dynamic Gut Model Is Reproducible, Colon Region Specific, and Selective for Bacteroidetes and Clostridium Cluster IX. Appl Environ Microbiol 2010;76:5237-46.

Van den Bogert B. Community and genomic analysis of the human small intestine microbiota. Thesis, Wageningen University and Research, Wageningen, 2013.

van Nuenen MHMC, Meyer PD, Venema K. The effect of various inulins and Clostridium difficile on the metabolic activity of the human colonic microbiota in vitro. Microb Ecol Health Dis 2003;15:137-44.

Venema K, van den Abbeele P. Experimental models of the gut microbiome. Best Pract Res Clin Gastroenterol 2013;27:115-26.

Walter J, Ley R. The Human Gut Microbiome: Ecology and Recent Evolutionary Changes. Annual Review of Microbiology, 65 Gottesman S, Harwood CS (eds). Palo Alto: Annual Reviews, 2011:411-29.
Wang M, Ahrne S, Jeppsson B et al. Comparison of bacterial diversity along the human intestinal tract by direct cloning and sequencing of $16 \mathrm{~S}$ rRNA genes. FEMS Microbiol Ecol 2005;54:219-31.

Wang X, Heazlewood SP, Krause DO et al. Molecular characterization of the microbial species that colonize human ileal and colonic mucosa by using 16S rDNA sequence analysis. J Appl Microbiol 2003;95:508-20.

Willing BP, Dicksved J, Halfvarson J et al. A pyrosequencing study in twins shows that gastrointestinal microbial profiles vary with inflammatory bowel disease phenotypes. Gastroenterology 2010;139:1844-U1105.

Youngberg CA, Berardi RR, Howatt WF et al. Comparison of gastrointestinal $\mathrm{pH}$ in cystic-fibrosis and healthy-subjects. Dig Dis Sci 1987;32:472-80.

Zoetendal EG, Heilig H, Klaassens ES et al. Isolation of DNA from bacterial samples of the human gastrointestinal tract. Nat Protoc 2006;1:870-3.

Zoetendal EG, Raes J, van den Bogert B et al. The human small intestinal microbiota is driven by rapid uptake and conversion of simple carbohydrates. ISME J 2012;6:1415-26. 